\title{
Apples, Arts, Amnesiacs and Emigrants: The University Connection
} Author(s): Patricia Palmer

Source: The Irish Review (1986-), No. 8 (Spring, 1990), pp. 14-18

Published by: Cork University Press

Stable URL: https://www.jstor.org/stable/29735508

Accessed: 19-08-2019 11:02 UTC

JSTOR is a not-for-profit service that helps scholars, researchers, and students discover, use, and build upon a wide range of content in a trusted digital archive. We use information technology and tools to increase productivity and facilitate new forms of scholarship. For more information about JSTOR, please contact support@jstor.org.

Your use of the JSTOR archive indicates your acceptance of the Terms \& Conditions of Use, available at https://about.jstor.org/terms

Cork University Press is collaborating with JSTOR to digitize, preserve and extend access to The Irish Review (1986-) 


\title{
Apples, Arts, Amnesiacs and Emigrants: the University Connection
}

\author{
PATRICIA PALMER
}

On 14 September 1989, the Taoiseach, Charles J. Haughey unveiled a stout granite stone at the entrance to what had been up to then the National Institute for Higher Education, Limerick. The front face of the stone bears the institution's new name: 'University of Limerick' and - in significantly smaller lettering - 'Ollscoil Luimnigh'. On the reverse side, however, carved into the stone in celtic lettering, there is a curious legend:

And pluck till time and times are done

The silver apples of the moon,

The golden apples of the sun.

The appropriation of Mr Yeats's lines as a motto, of sorts, for the erstwhile 'Technological University' seems, at first sight, a curious blend of whimsy and incongruity: this is hardly an institution where studious youth is encouraged to dabble in dreams, 'to walk among long dappled grass' or pluck . . . anything.

The spectacle of an institution dismissive of the place of the arts - as anything other than quaint heraldry - invoking Yeats's benediction for its vision of relevance and salvation-through-technology is richly ironic.

It is worth locating more precisely the exact nature of this paradox. For the opposition on which it rests - between the 'relevant', narrowly defined, and the implicitly 'irrelevant' - conveniently marks the co-ordinates in a debate that must be joined. For from this dialectic will emerge a definition of what universities are and what they do to take us into the twenty-first century.

The paradox derives its pungency from the new University's relationship with the arts. It is instructive to listen to the university's president on the topic (and, in the absence of a University senate or other representative body, it is hardly relevant to listen to anyone else). According to Dr Walsh, an arts degree is 'a rather narrow experience . . . relevant for a previous generation, a previous century, but technology and science are the driving force of this age'. The arts are external to the 'mission' of a mould-breaking, technology-preoccupied institution; they are a form of dalliance best left aside until one has qualified in an area 
deemed 'relevant'. Thereafter, they are - seemingly - modest accomplishments, effortlessly acquired. ${ }^{1}$

Twenty-four hours after the stone's unveiling, the University's new President was addressing its latest graduates. His speech was that of a jaunty victor, playful at the expense of the tired follies and brittle idealisms of many of the institutions his own had so recently come to join. In his speech, the paradox ripened. Whereas, he told the graduates, U.L. was both 'excellent and relevant', many of the older universities 'excelled at being irrelevant'. Clearly, the time has come for definitions to be produced: 'relevant' to what? ('Life?' Liberty? The pursuit of happiness? Making $20 \mathrm{~K}$ at $25 \%$ tax rates?); relevant to whom? (The individual graduates? The travellers encamped at U.L.'s gates? London stockbroking firms? IDA-lured multinationals?).

This must be returned to but, for the present, one thing at least is clear: plucking these dreams, these wistful idealisms that Yeats symbolised in the golden, silver apples is not relevant; and studying Yeats, symbolism and apples certainly has no place in the relevant scheme of things . . .

Yet, as the words carved in stone attest, even such centres of 'excellence and relevance' occasionally feel the atavistic pull to invoke the benediction of 'Great Art'. It is indeed a role art has become accustomed to under market capitalism's heady reign: art press-ganged into validating forces alien or even hostile to it. There is much in a campus bristling with semiotic interest to show that that impulse is busily at work in Limerick. Consider the national Self-Portrait Collection, that slightly uneasy invitation to solipsism exhibited in Plassey House. Or Plassey House itself - referred to, apparently without irony, as 'the White House' - a porticoed mock-Palazzo that calls on all the validating power of the old - the elk-bones in the vestibule, the gentlemen's club atmosphere of the University Club, the aristocratic parkland outside - to bolster its purchase on the new.

It would be just whimsy of another kind, however, to play this simply as a semiotic game (however suggestive the insights it may bring ${ }^{2}$ ). For while we do so, the agenda for the universities of the future is being set: functionalist, utilitarian, remorseless in their pursuit of a soi-disant relevance. And, as we have seen, invoking as they do so art's blessing for this development, in a process that emasculates art and drains it of its critical power.

It is a process which our Marxist friends have long taught us to recognize as the perfidious deed of high commerce, neutering art even as it patronises it. It is considerably more chilling, therefore, to watch a university (traditional defender of art's power as an unindentured critical force, rigorously interrogating what passes for 'true' or 'self-evident' in society) joining in this process. Chilling but unsurprising.

For the well-spring of culture from which U.L. sips is Enterprise Culture. And 
it is from Enterprise Culture, therefore, that it takes its definition of 'relevant'. What is relevant to U.L. is that which is relevant to the operation of the freemarket. It will supply the market with the skills and, almost more importantly, the attitudes it needs. The critical imagination that might challenge this definition of the 'relevant' is far from being 'irrelevant': its analytical impulse rather is all too pertinent - and therefore excluded.

And so the arts with their awkward, quizzical energies, must be sidelined. Their import must be denied, they must be belittled in the market place as spent forces. Their husks can then be taken over as empty fetishes to adorn the new order. There is nothing casual in this concerted trivialization: rather, the stage is being cleared of the one agency that might question too pressingly this marketled experiment in university education.

The forced dichotomy between the 'relevant' and the 'irrelevant' springs from ideological imperatives: it is an artificial construct. And, in the disarming manner of such artifices, it is liable to deconstruct itself. The excluded term - 'the arts' - cannot be so lightly dismissed from engagement with the late twentieth century. Instead, as we shall see, by exposing the paradoxes and absences in the excluding term - 'the relevant' - it reveals the artificality of that dichotomy.

The attempted disjunction is brought intriguingly together in the matter of Europe. For 'Europe' is at once that increasingly narrow-seeming business club of the Single Market and a wider spiritual entity bonded by historical, artistic and humanist traditions. Thus, to those who seek easy dichotomies, who want to introduce hierarchies and excluded orders, Europe presents particular challenges. For its richness and strength lies in its very multiplicity, in its synthesis of what sectional interests would seek to separate. Europe is the Europe both of the Renaissance and the Hanseatic League; of the Enlightenment and the Coal and Steel Community; of Milton as well as Newton, of Rousseau as well as Hobbes. Any attempt to construct false oppositions and exclusions purportedly in the name of what is relevant to Europe - is difficult to sustain in that context. Let us then watch the artifice begin to unravel itself - obliquely at first - and move to 'Europe', as so many of our graduates do through emigration.

If the choice of lines from 'The Song of Wandering Aengus' has been seen up to this as wholly inapposite and paradoxical, it may now be necessary to modify that view. For, one wonders, might not its selectors have been struck by the poem's picture of Aengus 'old with wandering through hollow lands', recognising in it perhaps a refracted image of exile and emigration? After all, much more than with plucking apples, this University is associated in the public mind with exhortations to emigration. Such urgings follow logically from its free-market philosophy.

Last September, speaking to graduating students at the end of a summer 
where Irish politicians, apparently without embarrassment, had spent much time soliciting the United States to take still more of our unemployed, Dr Walsh returned to the theme which had aroused some controversy last year. Proudly unrepentant, he told the graduates that he would be reaffirming that earlier advice: seize the day and go to Europe.

With, one assumes, unintentional irony, the President moved from this exhortation, turning to celebrate the collapse of socialism (a condition to which, he suggested, Ireland had to a modest degree succumbed; and to which our present tax woes were attributable . . .). The young people streaming out of East Germany to freedom in the West, he averred, symbolised the failure of socialism. The placement is richly ironic: if in one moment, emigration (from East to West Germany) can be taken as an index of the collapse of socialism, then our emigration, with its annual outflow of 50,000 people, can hardly, moments later, be taken as a ringing affirmation of the free market system. Here is a paradox that undoes itself.

The far more serious paradox, however, arises from the attempted exclusion of the arts from inside the charmed circle of the 'relevant', in the context of Europe. As we have seen, Europe is a rich weave: so, if one vital thread of that weave is peremptorily ripped out and cast aside as a passé irrelevancy, then a full account of the matter of Europe cannot be given. Yet it is within this interesting lacuna that the new University's Humanities School and European Studies Department increasingly finds itself operating.

The School of Humanities - the choice of name is neo-Orwellian - is less an arts faculty than its deliberate replacement. Just as the University was seen earlier to empty the arts of their real meaning, so the Humanities School hollows out the recognised forms of an arts programme and fills them instead with unfamiliar shapes and simulacra.

Thus the courses themselves - with titles like 'Property and Pecuniary Insurance' - are narrowly described and functional. Moreover, they are placed within a module system (five new subjects studied in each ten week term) which encourages superficial learning and the short-term accumulation of facts. The module system delivers capsules of facts in short bursts and, therefore, is wellenough suited to some technical subjects with a defined factual load. What it cannot offer, however, is a framework for exploration in depth, wide reading or sustained thought. To peg 'humanities' subjects into such a hostile matrix is, inevitably, to do violence to them. An absence is built into the very fabric of the system: of the time for thoughtful reading or for analysis. This is a system where even 'Politics' can be examined by multiple choice questions, liberated from the possibility of analysis or interpretation. No plucking 'till time and times are done' here. Thus, Europe becomes a list of 500 regulations and standardized plug sizes; of insurance legislation; of 'applied language teaching', of linguistic 
forms robbed of cultural content. This is the Amnesiac's Europe, a new Pacific Basin, razed of memory, forgetful of both its social and cultural context. This is a Europe made in Taiwan.

Significantly, it was indeed to the Pacific Basin that Dr Walsh, speaking at the inauguration, turned to find a model for the future development of the new university. It would be looking for inspiration not to the older (European) universities with their lamentable penchant for the 'irrelevant' - but to Japan and its 'Technopoli'.

Against all of this background, then, the selection of Yeats's lines to validate enterprises so contrary to his vision seems giddily inappropriate. But in Responsibilities (1914), Yeats had already anticipated such audacious pilfery - and refused to sanction it.

\author{
I made my song a coat \\ Covered with embroideries \\ Out of old mythologies \\ From heel to throat; \\ But the fools caught it, \\ Wore it in the world's eyes \\ As though they'd wrought it. \\ Song let them take it \\ For there's more enterprise \\ In walking naked.
}

('A Coat')

For the rest of us, however, who indeed want our students to pluck the golden and silver apples, to enjoy life whole and in the round, there is a need to recognise the strength of the forces now setting the agenda for the development of university education - and to insist that the lines of the 'relevant' cannot be so narrowly drawn. For wilful polarities and exclusions can ultimately only disable the pursuit of both knowledge and excellence. The critical spirit, the understanding, the joy and the sheer life that the arts bring can be kept outside the university gates only at the price of impoverishmnt and constriction - to the 'excellent' citizenry within just as much as the excluded rag-and-bone men of the heart without.

1 cf. Hanley's People RTE 1 (7:11:88); DrWalsh, added: 'One can readily read after pursuing one's degree . . . and become actively involved in the arts'.

2 Consider, for example, the newest-named of the university's 'towers'. In February, 1987, the Kate O'Brien tower joined the Boyle, Burke, Bianconi, Dargan, Ferguson, Hamilton, Harvey, McLoughlin, Mallet, Merriman, Murphy and Tyndall towers, in belated recognition of two sectors that are, apparently, easily overlooked: artists and women. 